Research, Society and Development, v. 7, n. 12, p. 01-22, e2712478, 2018

ISSN 2525-3409 (CC BY 4.0)

A educação ambiental com perspectiva transdisciplinar no contexto da legislação brasileira

The environmental education with a transdisciplinary perspective in the context of the Brazilian legislation

Fernanda Beatryz Rolim Tavares Universidade Federal de Campina Grande - UFCG, Brasil

E-mail: nanda_sodi@hotmail.com Fernando Chagas de Figueiredo Sousa Instituto Federal da Paraíba, Brasil E-mail: sousaf.figueiredo@gmail.com Vanessa Érica da Silva Santos Universidade Federal de Campina Grande - UFCG, Brasil E-mail: vanessa.erica@hotmail.com Recebido: 17/06/2018 - Aceito: 15/07/2018

\title{
Resumo
}

A legislação brasileira trata sobre a necessidade de implantar no país práticas acerca da Educação Ambiental, envolvendo como um componente essencial e permanente da educação nacional, devendo estar presente em todos os níveis e modalidades do processo educativo, seja em caráter formal e não formal. Não deve ser retratada apenas como uma disciplina, mas como uma prática educativa integrada e que seja incluída nos mais diversos temas abordados com os alunos. O objetivo do presente estudo é apresentar a inter-relação da Educação Ambiental como perspectiva transdisciplinar com os Sistemas de Gestão Ambiental, envolvendo o contexto da legislação brasileira. Destaca também quanto a importância, discute aspectos da Gestão Ambiental, a transdisciplinaridade com um método auxiliar, além de indicar a Educação Ambiental como fator de sensibilização para a Gestão Ambiental. O trabalho foi desenvolvido através de pesquisa bibliográfica, para a compreensão das propostas educacionais acerca da Educação Ambiental. Pode-se perceber que a Educação Ambiental é capaz de atuar como um Instrumento de Gestão Ambiental eficaz e eficiente, onde se busca trabalhar conceitos, valores e comportamentos da sociedade como um todo, podendo se aliar a outros instrumentos econômicos de controle com finalidade de contribuir para a construção de uma sociedade a qual prioriza o equilíbrio de todo o meio ambiente. 
Palavras-chave: Educação Ambiental; Sustentabilidade; Transdisciplinaridade; Gestão Ambiental.

\begin{abstract}
The Brazilian legislation deals with the implication of a country in relation to Environmental Education, as an essential and permanent component of national education, and must be present at all levels and forms of educational process, both formal and non-formal. It should not be portrayed as a discipline, but an integrated educational practice that should be used as a whole. The present study is presented in an interdisciplinary and environmental way as a transdisciplinary perspective with the Environmental Management Systems, considering the context of the Brazilian legislation. Emphasis is placed on the importance of environmental management issues, transdisciplinarity with auxiliary assistance, as well as a working environment for environmental awareness. The work was developed through bibliographical research, with the purpose of obtaining information on Environmental Education. You may be able to evaluate the ability to behave as an efficient and environmental control tool whenever it works with concepts, values and behaviors as a whole, while at the same time other control instruments can contribute to the construction of a society with priority and balance of the whole environment.
\end{abstract}

Keywords: Environmental education; Sustainability; Transdisciplinarity; Environmental management.

\title{
1. Introdução
}

Inúmeros problemas surgem relacionados ao meio ambiente, trazendo consigo a necessidade de um desenvolvimento de ações voltadas para a sua preservação e recuperação, bem como incentivar e conscientizar os cidadãos, tendo em vista que estes são os maiores responsáveis pelos problemas ambientais, pois diante o consumismo exagerado presente atualmente tornam-se um dos fatores determinantes para que estes problemas se compliquem cada vez mais. No momento em que se altera o meio ambiente ou interfere no ecossistema ocasiona-se um desequilíbrio de tudo que foi desenvolvido pela natureza até aquele momento, gerando consequências que podem ser temporárias ou permanentes e nem sempre pode ser presumida por existir uma grande complexidade. O sistema de gestão ambiental é um conjunto de procedimentos que visa organizar, controlar e diminuir os impactos gerados no 
meio ambiente, fundamentando-se no cumprimento das legislações ambientais vigentes e na melhoria do desempenho ambiental.

Mesmo com o desenvolvimento de diversas políticas públicas voltadas a preservação do meio ambiente, o desequilíbrio ecológico vem aumentando cada vez mais e gerando maior preocupação com o futuro do planeja. Surge, então, a necessidade da sociedade se organizar objetivando promover a Educação Ambiental, um processo de formação e informação que promove o desenvolvimento da consciência crítica das pessoas em relação aos problemas ambientais e leva a percepção da necessidade de participar e fiscalizar as condições ambientais como um agente ativo.

A Lei $\mathrm{n}^{\circ}$ 9.795, de 27 de abril de 1999, estabelece a necessidade de implantar no país a prática da Educação Ambiental como um componente necessário e permanente da educação nacional, para todos os níveis e modalidades do processo educativo, seja de modo formal ou não-formal. Não deve ser retratado como uma disciplina, mas como uma prática educativa integrada e que seja incluída nos mais diversos temas abordados com os alunos. Esse é um processo que trata de construir valores de forma coletiva visando o social, conhecimentos, habilidades, atitudes e competências voltadas para a conservação do meio ambiente.

A Gestão ambiental surgiu no meio educacional como um instrumento para instruir e conscientizar o comportamento das pessoas, buscando manter, em sociedade, ações de sustentabilidade focando as suas responsabilidades individuais do ser humano como membro do meio ambiente. Essa consciência ecológica vem aumentando visivelmente na sociedade em diferentes níveis. Implantar essa prática da gestão ambiental em uma abordagem transdisciplinar propicia o conhecimento e a capacidade crítica de perceber, dialogar e agir com medidas importantes de forma contínua e permanente.

A Gestão Ambiental objetiva criar recursos técnicos, projetar, estruturar e administrar atividades, tanto econômicas como sociais, de maneira a utilizar racionalmente os recursos naturais, cumprindo com a legislação ambiental. Então, a Educação Ambiental ao atuar como um instrumento de Gestão Ambiental pode se tornar eficaz e eficiente, mudando valores, conceitos e comportamentos dos seres humanos.

O presente estudo busca discutir esses conceitos relacionados a consciência ética e como esse processo é desenvolvido nas instituições de ensino, visando o meio da transdisciplinaridade, a qual envolve o aluno no contexto ambiental de modo integrado aos demais conteúdos, sem a distinção, objetivando apresentar de forma conceitual a inter-relação da Educação Ambiental como perspectiva transdisciplinar com os Sistemas de Gestão Ambiental. O trabalho foi desenvolvido através de pesquisa bibliográfica para a compreensão 
das propostas educacionais acerca da Educação Ambiental, discutir o envolvimento com a Gestão Ambiental, discutir aspectos da Gestão Ambiental, abordar a transdisciplinaridade com um método auxiliar na Educação Ambiental e apresentar a importância da Educação Ambiental, numa abordagem conceitual.

\section{Referencial Teórico}

\subsection{Educação Ambiental: Problemas e Perspectivas}

Problemas ambientais vêm aumentando cada vez mais, mesmo com o desenvolvimento de políticas públicas voltadas para a preservação do planeta que foram elaboradas a partir da preocupação com o futuro, surgindo com caos total que o meio ambiente se encontrava, preocupação essa que levou a sociedade a se organizar com o objetivo de promover a Educação Ambiental.

Castro (2004) diz que a educação ambiental constitui em uma área de conhecimento eminente interdisciplinar em diversos fatores interligados e necessários, sendo assim a educação ambiental não pode ser concebida apenas como conteúdo escolar, pois busca uma consciência de uma complexa rede de fatores políticos, econômicos, culturais e científicos. Para o autor, a construção de campos conceituais é indispensável para a compreensão crítica dessa dimensão da realidade, essencial para a qualidade de vida. Os conceitos abordam tanto os mais simples como florestas e fauna, quanto aos mais abstratos como politica, democracia, meio ambiente, dentre outros.

De acordo com Silva (2012), a Educação Ambiental é considerada um ramo da educação que objetiva a disseminação do conhecimento sobre o ambiente, buscando auxiliar na sua preservação e manter a sustentabilidade de seus recursos, em um processo permanente no qual os indivíduos e a comunidade a partir do conhecimento, tomem consciência de suas ações e possam agir em busca de soluções para os problemas ambientais presentes e futuros, podendo levar à mudança de valores e comportamentos.

Silva e Pessoa (2013) reforçam que uma atividade de educação Ambiental deve ser constituída como um processo contínuo, envolvendo indivíduos e comunidades para se conscientizarem da possibilidade de um colapso ecológico e que possam adquirir conhecimentos, valores, habilidades, experiências e determinação que os tornem aptos a agir.

Medina (2001) trata a Educação Ambiental como processo que consiste em propiciar às pessoas uma compreensão crítica e global do ambiente, explanando valores e desenvolvendo atitudes que os tornem conscientes e participativos em relação a conservação e a adequada utilização dos recursos naturais, objetivando a qualidade de vida e a eliminação da pobreza extrema e do consumismo desenfreado. 
A partir desses critérios, Adams (2012) enfoca que a Educação Ambiental se trata de um processo que não pode ser instalado como uma disciplina específica, mas deve estar presente em todas as ações educativas. É um processo que promove a compreensão crítica e global, sistematizado, por isso a interdisciplinaridade; trata-se de um processo que evidencia valores buscando a equidade, estimulando a participação, promovendo a cidadania e a consciência ambiental. Conclui ainda que, não se trata de uma tarefa fácil a de educar para a sustentabilidade ambiental, uma vez que pretende estimular mudanças nos hábitos culturais, sociais e econômicos para alterar costumes que promovem o consumismo e priorizam o desenvolvimento econômico.

O trabalho educacional é componente dessas medidas das mais essenciais, necessárias e de caráter emergencial, pois sabe-se que a maior parte dos desequilíbrios ecológicos está relacionada a condutas humanas inadequadas impulsionadas por apelos consumistas - frutos da sociedade capitalista - que geram desperdício, e ao uso descontrolado dos bens da natureza, a saber, os solos, as águas e as florestas (CARVALHO, 2006).

Sendo assim, diante uma sociedade capitalista que impulsiona a condutas humanas desfavoráveis ao meio ambiente, faz-se necessário medidas que visem combater, de forma urgente, esse descontrole da utilização dos bens que o meio ambiente oferece. A educação tratada como base, pode auxiliar desde cedo em um processo de compreensão sobre a sustentabilidade em todos seus âmbitos, onde a ideia central é partir da conscientização do indivíduo, para assim, iniciar um processo construtivo.

\subsection{Política Nacional De Educação Ambiental}

A Constituição Federal, em seu artigo $225, \S 1^{\circ}$, diz que é obrigação do Poder Público: "Promover a educação ambiental em todos os níveis de ensino e a conscientização pública para a preservação do meio ambiente." (art.225, § $1^{\mathrm{o}}$, VI).

Machado (2011) trata de duas atividades que estão preconizadas na Constituição: a promoção da educação ambiental e a promoção da conscientização pública. Promover a educação ambiental em todos os níveis de ensino é inserir a transmissão do conhecimento sobre o meio ambiente no ensino escolarizado.

A Lei $n^{\circ}$ 9.795, de 27 de abril de 1999, institui a Política Nacional de Educação Ambiental, que visa inserir a Educação Ambiental como uma parte necessária da educação nacional, estando presente em todos os níveis e modalidades do processo educativo, de modo formal e não-formal. Deve ser inserido como tema transversal, sem constituir disciplina específica, como uma prática educativa compartilhada com todos os professores, que devem ser treinados para incluir o tema nos diversos assuntos abordados com os alunos. 
Research, Society and Development, v. 7, n. 12, p. 01-22, e2712478, 2018

ISSN 2525-3409 (CC BY 4.0)

Entende por educação ambiental tudo aquilo que o indivíduo e a coletividade constroem, sendo com valores sociais, sabedoria, aptidão, atitudes e competências focadas para conservar o meio ambiente, essencial a uma qualidade de vida e sua sustentabilidade. Sendo assim, Sabbagh (2011) diz que a educação ambiental é um item necessário e permanente da educação nacional.

Em seu artigo $5^{\circ}$, PNEA aborda sobre os objetivos fundamentais, que consideram desenvolver uma percepção integrada do meio ambiente em suas relações, envolvendo diversos aspectos; promove a democratização das informações ambientais; estimula e fortalece a consciência crítica sobre problemas ambientais e sociais, busca incentivar a participação de todos na preservação do meio ambiente; estimula à cooperação entre diversas regiões do país para tentar construir uma sociedade equilibrada ambientalmente; busca fortalecer a integração ciência e tecnologia; e traz o fortalecimento da cidadania, autodeterminação dos povos e solidariedade como fundamentos para o futuro da humanidade.

$\mathrm{O}$ artigo $9^{\circ}$ da PNEA reforça obrigatoriedade da Educação Ambiental que deve estar presente em todos os níveis educacionais (da educação básica à educação superior) e aplicada tanto às modalidades existentes, quanto àquelas que vierem a ser criadas ou reconhecidas pelas leis educacionais, englobando também a educação no campo e outras.

Sob o enfoque informal, Pereira (2010) diz que a Educação Ambiental está presente em todas as manifestações voltadas para o respeito e resguardo da coletividade, a qual abrange desde os aprendizados vindos da convivência parental, ao diálogo entre amigos no trabalho e em momentos de descontração, não havendo método específico para ensiná-la, nem para aprendê-la, devido a sua intensidade e abrangência. O que acontece é a falta de conhecimento, pois muitas pessoas não sabem que a Educação Ambiental também está presente no cotidiano, uma das razões pelas quais deixam de enfatizá-la no dia-a-dia. Por tal motivo a legislação acrescentou nos incisos do parágrafo único do art. 13 o incentivo do Poder Público aos projetos desenvolvidos na educação não-formal.

\subsection{O Meio Ambiente e a Legislação Brasileira}

De acordo com Sabbagh (2011), o primeiro passo que o Brasil deu com relação ao meio ambiente foi quando a Constituição Federal de 1988 dedicou um capitulo inteiro a este assunto, sendo um dos impactos mais significativos do avanço do ideal do desenvolvimento sustentável vindo da atuação dos movimentos realizados, desenvolvendo um compromisso do país com o desenvolvimento sustentável e a manutenção do meio ambiente equilibrado.

A Constituição Federal de 1988 trata sem seu artigo 225, Capítulo VI - Do Meio Ambiente, da Constituição da República Federativa do Brasil: "Todos têm direito ao meio 
ambiente ecologicamente equilibrado, bem de uso comum do povo e essencial à sadia qualidade de vida, impondo-se ao poder público e à coletividade o dever de defendê-lo e preservá-lo para as presentes e futuras gerações”.

Machado (2011) pondera que todos devem ter direito ao meio ambiente ecologicamente equilibrado. Esse equilíbrio ecológico é considerado como um estado de equilíbrio entre diversos fatores que formam o ecossistema, suas cadeias tróficas, vegetação, clima, etc., que podem ser desestabilizados pela ação humana de alguma maneira. Isso não significa condições naturais que não sejam alteradas de forma alguma, mas que deve haver uma harmonia entre vários elementos que compõe a ecologia.

A Constituição trata ainda do estabelecimento de competências da União, dos Estados, do Distrito Federal e dos Municípios, onde é dever do poder público e à coletividade defendêlo e preservá-lo para as presentes e futuras gerações. Aborda ainda, em seu artigo 225, os princípios de restauração, recuperação e reparação do meio ambiente, onde "todos têm direito ao meio ambiente ecologicamente equilibrado, bem de uso comum do povo e essencial à sadia qualidade de vida, impondo-se ao poder público e à coletividade o dever de defendê-lo e preservá-lo para as presentes e futuras gerações." Em seu $\S 3^{\circ}$ do artigo 225 , consta a obrigação de reparar os danos causados ao meio ambiente, tanto por pessoas físicas ou jurídicas, sujeitos a sanções penais e administrativas. $O \S 2^{\circ}$ diz ainda que: "Aquele que explorar recursos minerais fica obrigado a recuperar o meio ambiente degradado, de acordo com solução técnica exigida pelo órgão público competente, na forma da lei.”.

Machado (2011) diz que a recuperação do Meio Ambiente passou, constitucionalmente, a fazer parte dos processos de exploração de recursos minerais, onde nenhum órgão publico poderá autorizar qualquer pesquisa ou lavra mineral em que não esteja prevista a recuperação ambiental. A legislação não poderá ser complacente ou omissa com os que deixarem de cumprir o que diz o $\S 2^{\circ}$ do artigo 225.

A Lei No 6.938, de 31 de Agosto de 1981dispõe sobre a Política Nacional do Meio Ambiente, seus fins e mecanismos de formulação e aplicação, e dá outras providências. Essa política tem por objetivo a preservação, melhoria e recuperação da qualidade ambiental propícia à vida, visando assegurar condições para se desenvolver sócio-economicamente, para interesses da segurança nacional bem como à proteção da dignidade da vida humana e vem tentando abranger os seguintes princípios:

[...]I - ação governamental na manutenção do equilíbrio ecológico, considerando o meio ambiente como um patrimônio público a ser necessariamente assegurado e protegido, tendo em vista o uso coletivo;

II - racionalização do uso do solo, do subsolo, da água e do ar;

Ill - planejamento e fiscalização do uso dos recursos ambientais; 
IV - proteção dos ecossistemas, com a preservação de áreas representativas; $\mathrm{V}$ - controle e zoneamento das atividades potencial ou efetivamente poluidoras; VI - incentivos ao estudo e à pesquisa de tecnologias orientadas para o uso racional e a proteção dos recursos ambientais;

VII - acompanhamento do estado da qualidade ambiental;

VIII - recuperação de áreas degradadas;

IX - proteção de áreas ameaçadas de degradação;

$\mathrm{X}$ - educação ambiental a todos os níveis de ensino, inclusive a educação da comunidade, objetivando capacitá-la para participação ativa na defesa do meio ambiente. (LEI No $6.938 / 81$, art. $2^{\circ}$ )

A partir da leitura do dispositivo retromencionado é notável a importância dada pelo legislador brasileiro a temática, no entanto, verifica-se que a lei fora promulgada em 1981 e ainda se aparenta muito distante de ter eficácia.

Quando foi previsto no inciso I uma ação governamental para manutenção do equilíbrio ecológico, é preciso que o poder público crie políticas públicas de implementação a longo prazo, pois uma norma programática deve ser observada do ponto de vista prático.

Cabe ressaltar que a legislação é bem completa ao mencionar as necessidades para preservação ambiental, prevendo no inciso III o planejamento e fiscalização do uso de recursos naturais, entre outras previsões que só demonstram que o legislador quis aplicação concreta e cooperada do poder público para trazer eficácia de educação ambiental para os brasileiros, sendo necessário, portanto, trazer através de políticas públicas a efetividade da norma.

Nesse contexto, precisamos usar a educação ambiental como ferramenta indispensável na execução da preservação ambiental. Ademais, a educação no contexto atual não pode ser levada sem tomar por base os problemas sociais atuais.

A definição de educação ambiental se faz por meio de múltiplas e diferentes ideias, correntes e manifestações; mas são definições relativamente similares. Na obra Identidades da Educação Ambiental Brasileira tem-se a seguinte definição: Educação Ambiental portanto é o nome que historicamente se convencionou dar às práticas educativas relacionadas à questão ambiental. Assim, "Educação Ambiental" designa uma qualidade especial que define uma classe de características que juntas, permitem o reconhecimento de sua identidade, diante de uma Educação que antes não era ambiental (MINISTÉRIO DO MEIO AMBIENTE, 2004).

Para Sabbagh (2011), a Política Nacional do Meio Ambiente trabalha os conceitos, objetivos específicos, diretrizes e institui o Sistema Nacional do Meio Ambiente, o Conselho Nacional do Meio Ambiente e os instrumentos da política. Os órgãos e entidades da União, dos Estados, do Distrito Federal, dos territórios e dos Municípios, bem como as Fundações instituídas pelo Poder Público, são responsáveis pela proteção e melhoria da qualidade ambiental, são eles que constituem o Sistema Nacional do Meio Ambiente (SISNAMA), 
como um conjunto articulado de organizações, regras e práticas. Este sistema é composto por um Órgão Superior, um Órgão Consultivo e Deliberativo; um Órgão Central; um Órgão Executor; Órgãos Seccionais e Órgãos Locais.

O Ministério do Meio Ambiente (MMA) foi criado em novembro de 1992, com missão de promover a adoção de princípios e estratégias para o conhecimento, a proteção e a recuperação do meio ambiente, o uso sustentável dos recursos naturais, a valorização dos serviços ambientais e a inserção do desenvolvimento sustentável na formulação e na implementação de políticas públicas, de forma transversal e compartilhada, participativa e democrática, em todos os níveis e instâncias de governo e sociedade.

A Política Nacional do Meio Ambiente traz em seu texto que irá visar:

I - à compatibilização do desenvolvimento econômico-social com a preservação da qualidade do meio ambiente e do equilíbrio ecológico;

II - à definição de áreas prioritárias de ação governamental relativa à qualidade e ao equilíbrio ecológico, atendendo aos interesses da União, dos Estados, do Distrito Federal, dos Territórios e dos Municípios;

III - ao estabelecimento de critérios e padrões de qualidade ambiental e de normas relativas ao uso e manejo de recursos ambientais;

IV - ao desenvolvimento de pesquisas e de tecnologias nacionais orientadas para o uso racional de recursos ambientais;

$\mathrm{V}$ - à difusão de tecnologias de manejo do meio ambiente, à divulgação de dados e informações ambientais e à formação de uma consciência pública sobre a necessidade de preservação da qualidade ambiental e do equilíbrio ecológico;

VI - à preservação e restauração dos recursos ambientais com vistas à sua utilização racional e disponibilidade permanente, concorrendo para a manutenção do equilíbrio ecológico propício à vida;

VII - à imposição, ao poluidor e ao predador, da obrigação de recuperar e/ou indenizar os danos causados e, ao usuário, da contribuição pela utilização de recursos ambientais com fins econômicos. (LEI $\mathrm{N}^{\circ} 6.938 / 81$, art. $4^{\circ}$ ).

A previsão legislativa supramencionada traz a abordagem coercitiva que deve ser dada na implantação de medidas de preservação, já que para trazer eficácia de cumprimento, devese impor uma forma de coerção estatal, e assim a mesma realizou ao, por exemplo, prever no inciso VII à obrigação do poluidor de recuperar ou indenizar os danos ambientais decorrente de suas ações. Nesse ponto cumpre-se observar que a opção de indenizar não pode ser vantajosa ao poluidor, pois se assim for, o mesmo continuará poluindo, haja vista que ainda estará lucrando. A pecúnia deve ser alta, de forma a coagir a empresa a não poluir mais, pois se assim não for, estaríamos vendendo o nosso meio ambiente equilibrado para as empresas. O caráter é sancionatório e preventivo de novas condutas e este deve ser observado em todas as ações protetivas, para que a letra da lei não se torne apenas um texto sem aplicabilidade. Ademais, muitos educadores acreditam que a educação ambiental como instrumento de aprendizagem pode gerar um comportamento ambiental responsável nas pessoas. 
De acordo com Hargreaves e Fink (2007) o aprendizado é uma preparação para a vida e também uma parte da vida. O sentido do aprendizado está embasado no sentido da vida. Empreende a busca por saber, por compreender, por comunicar e por deixar o mundo um lugar melhor.

Sabbagh (2011) considera que em 1989 foi fundado o IBAMA, substituindo o IBDF e da SEMA, com finalidade de unificar a política ambiental. O IBAMA consolida as Superintendências - Sudepe (do Desenvolvimento da Pesca) e Sudhevea (do Desenvolvimento da Borracha), herdando as funções e a infraestrutura de ambos. Em 2007, criou-se o Instituto Chico Mendes, que passa a ser o único órgão federal responsável pela gestão das áreas protegidas.

A lei $n^{\circ} 6.938 / 81$ em seu artigo $9^{\circ}$ retrata ainda sobre os instrumentos da Política Nacional do Meio Ambiente, que são instituídos:

\footnotetext{
I. Estabelecimento de padrões de qualidade ambiental;

II. Zoneamento ambiental;

III. Avaliação de impactos ambientais;

IV. Licenciamento e revisão de atividades efetiva ou potencialmente poluidoras; V. Incentivos à produção e instalação de equipamentos e a criação ou absorção de tecnologia, voltados para a melhoria da qualidade ambiental;

VI. Criação de espaços territoriais especialmente protegidos pelo Poder Público federal, estadual e municipal, tais como áreas de proteção ambiental, de relevante interesse ecológico e reservas extrativistas;

VII. Sistema nacional de informações sobre o meio ambiente;

VIII. Cadastro Técnico Federal de Atividades e Instrumentos de Defesa Ambiental;

IX. Penalidades disciplinares ou compensatórias ao não cumprimento das medidas necessárias à preservação ou correção da degradação ambiental;

X. Instituição do Relatório de Qualidade do Meio Ambiente;

XI. Garantia da prestação de informações relativas ao Meio Ambiente, obrigando-se o Poder Público a produzi-las;

XII. Cadastro Técnico Federal de atividades potencialmente poluidoras e/ou utilizadoras dos recursos ambientais;

XIII. Instrumentos econômicos, como concessão florestal, servidão ambiental, seguro ambiental e outros.
}

Os instrumentos elencados são de extrema importância no contexto de educar e manter um desenvolvimento sustentável, pois ao estabelecer padrões e qualidade ambiental, licenciamentos e revisões de atividades poluidoras, bem como penalidades para os descumpridores, estão-se vinculando todas as esferas governamentais a adotar as referidas medidas indistintamente, ao passo que cobra da administração a criação de órgãos de fiscalização direta de tais condutas.

Neste ponto, cumpre-se destacar que deixar a fiscalização exclusiva do Ministério público de práticas ilícitas ambientais é incoerente para tratar de eficácia. É preciso se criar um órgão auxiliar de investigação de empresas que abusam do meio ambiente, pois apenas o 
Ministério Público e as polícias comuns até a presente data não se mostram eficiente para salvaguardar a referida temática.

\subsection{Gestão Ambiental}

Para Floriano (2007) os problemas ambientais acontecem quando se altera o meio, interferindo em qualquer parte ou fase de um ecossistema, ocasionando um desequilíbrio do que a natureza desenvolveu durante toda a evolução daquele sistema. Sendo assim, qualquer intervenção sobre um ecossistema gera consequências secundárias que podem ser temporárias ou permanentes, em diversos graus de amplitude e intensidade. Nem sempre pode ser presumido, podem ocorrer também imprevistos, pois a complexidade dos ecossistemas geralmente é grande e nem tudo sobre eles é conhecido.

A Resolução Conama n 306/2002 trata Gestão Ambiental como a condução, direção e controle do uso dos recursos naturais, dos riscos ambientais e das emissões para o meio ambiente, através da implementação de um Sistema de Gestão Ambiental. Essa adequação pode ser alcançada por meio da implantação e o aprimoramento contínuo das conformidades ambientais, seja prevista na lei ou em qualquer outro dispositivo legal. A gestão inicia-se com o atendimento às conformidades já existentes a qual busca-se sempre ampliar, necessitando de uma base de dados a serem trabalhados, contendo indicadores ambientais, cuja função é medir o que se estuda.

Para Alcântara et al. (2012), ao implementar a Gestão Ambiental deve-se criar técnicas, planejar, organizar e administrar atividades econômicas e sociais, utilizando os recursos naturais de modo consciente, bem como cumprir a legislação ambiental. Existe um caráter multidisciplinar, pois, podem atuar nesta área os mais diversos profissionais, desde que habilitados. É necessário tomar decisões em curto prazo para garantir a conservação e preservação da biodiversidade e, assim diminuir os impactos ambientais resultantes pela humanidade.

As Diretrizes Curriculares Nacionais para a Educação Ambiental em seu artigo $2^{\circ}$ trata a Educação Ambiental como uma dimensão da educação sendo atividade da prática social, trazendo um desenvolvimento no caráter social na relação do individuo com a natureza, com finalidade de torná-la uma prática social e de ética ambiental.

Em 1996 foi lançada internacionalmente a série de normas ISO 14000, que trazia como objetivo criar um sistema de gestão ambiental para auxiliar as organizações a se comprometerem com o meio ambiente e cumprirem. SILVA (2011) diz que a ISO 14000 é um conjunto de normas voluntárias, definidas pela ISO, com finalidade de padronizar a Gestão Ambiental nas empresas. A série ISO 14000 trabalha com seis grupos de normas, 
cada uma delas atendendo a um assunto específico da questão ambiental: Sistema de Gestão Ambiental (ISO 14001); Auditorias ambientais (14010, 14011 e 14012); Avaliação do desempenho ambiental (14031); Rotulagem ambiental (14020, 14021 e 14024); Aspectos ambientais em normas de produtos (15060); Análise do ciclo de vida do produto (14040). O objetivo maior da gestão ambiental definida pela ISO 14000 é a busca permanente de melhoria da qualidade ambiental dos serviços, produtos e ambiente de trabalho de qualquer organização pública ou privada.

3. A Gestão Ambiental no Contexto Educacional

Menezes (2001) aborda a importância do relacionamento professor-aluno na busca da aprendizagem como processo de construção de conhecimento, partindo de uma reflexão crítica das experiências e do processo de trabalho. O conceito de mediação pedagógica surgiu no contexto da "pedagogia progressista", que trata de uma nova relação professor-aluno e pela formação de cidadãos participativos e preocupados com a transformação e o aperfeiçoamento da sociedade. Até a década de 70, o sistema educacional brasileiro seguia uma abordagem de ensino conhecida como "pedagogia tecnicista", na qual cabia ao aluno apenas assimilar os conteúdos transmitidos pelo professor.

Para Layrargues (2006) a educação ambiental, antes de tudo, é Educação, onde nenhuma discussão a respeito das metas, objetivos e avaliação da educação ambiental pode deixar de abordar a perspectiva sociológica da Educação como um instrumento ideológico de reprodução das condições sociais. Sendo assim, a educação ambiental deveria ser enquadrada na perspectiva de uma prática pedagógica destinada seja a manter ou alterar as relações sociais historicamente construídas, mesmo que essa prática pedagógica não seja destinada exatamente ao convívio social, mas ao convívio humano com a natureza. O autor reforça que a educação ambiental não deveria ser deixada de fora desse enquadramento teórico, como se estivesse isenta da interação com a mudança social, como se a educação ambiental fosse, tal qual o ambientalismo fundamentalista, supra-ideológico.

Quintas (2009) considera que o ato pedagógico pode ser pensado como produto da articulação de um contexto, subjetividade, conteúdos, objetivos da aprendizagem, procedimentos metodológicos, dentre outros, portanto, a concepção metodológica também funciona como ideia reguladora durante o processo de seu planejamento e de sua realização. Esse ato pode assumir diferentes feições, dependendo das condições objetivas (infraestrutura, recursos financeiros, etc.) e subjetivas (disponibilidade de tempo, disposição para participar, etc.), o processo educativo pode ser curso, oficina, seminário, ciclo de debates ou qualquer outro tipo de arranjo pedagógico. 
Research, Society and Development, v. 7, n. 12, p. 01-22, e2712478, 2018

ISSN 2525-3409 (CC BY 4.0)

Layrargues (2002) fala sobre a Educação Ambiental crítica, que é um processo educativo eminentemente político, objetivando o desenvolver nos educandos uma consciência crítica acerca das instituições, atores e fatores sociais geradores de riscos e respectivos conflitos socioambientais, a qual busca uma estratégia pedagógica do enfrentamento de tais conflitos a partir de meios coletivos de exercício da cidadania, pautados na criação de demandas por políticas públicas participativas conforme a gestão ambiental democrática solicita. Sendo assim, deve-se focar no tipo de ecologização da educação e da sociedade e não no grau de incorporação da variável ecológica, pois à medida que a educação e a sociedade se ecologiza pela vertente hegemônica, ocorre uma gradual diluição dos conteúdos emancipatórios do discurso ambiental alternativo. No mesmo sentido, importante destacar o modelo de educação ambiental refletido e praticado em todos os espaços pedagógicos disponíveis: aquele que possui como eixo de atuação, a transformação ou a conservação social.

\subsection{A Educação Ambiental e a Transdisciplinaridade}

Basarab Nicolescu (2000) trata da necessidade indispensável de pontes entre as diferentes disciplinas que traduziu-se pelo surgimento, na metade do século $\mathrm{XX}$, da pluridisciplinaridade e da interdisciplinaridade.

Melo (2011) diz que apesar da proposta pluridisciplinar ultrapassar os muros das disciplinas, ainda permanece com foco na pesquisa disciplinar. Com relação a abordagem interdisciplinar propicia intercambio de métodos entre as disciplinas, porém reage do mesmo modo provocando a geração de novas disciplinas e continuando o processo multiplicação disciplinar.

Santana (2016) diz que a transdisciplinaridade é um enfoque pluralista do conhecimento objetivando atingir uma unificação do saber, sendo através de articulações entre várias faces de compreensão do mundo, unindo várias disciplinas para facilitar um exercício mais amplo da cognição humana. Esse exercício de um olhar múltiplo permite que atinja a abrangência do crescimento da complexidade do mundo pós-moderno, justificando-se como ideia da transdisciplinaridade como um fluir de ideias e de um movimento de reflexão sobre conceitos, modificando assim a forma como o homem se reconhece e procura entender o seu papel no mundo, interagindo com o universo.

Menezes (2001) relata que a ideia de transdiciplinaridade surgiu na necessidade de substituir o conceito de disciplinas, que configura-se pela departamentalização do saber em diversas matérias, a qual considera práticas educativas focadas em um paradigma de abordar cada disciplina fragmentada e isolada das demais, podendo resultar também na fragmentação 
das mentalidades, consciências e posturas ocasionando assim na perda da compreensão do ser, da vida, cultura e relações e inter-relações.

Rodrigues (2000) retrata que se vive em um período de mudanças extraordinárias seja com os meios de comunicação, saberes, ritmo cotidiano, e há a responsabilidade de gerir todas elas. A questão consiste em saber de que modo vem se realizando essas mudanças, com quais valores, em que sentido, através de que formas de agir. A transdisciplinaridade propõe agir sobre os saberes que vem produzindo com o tempo, atuando sobre valores, o modo de praticar questionando as "chamadas" novas competências individuais e coletivas, utilizando o aprendizado como experiência essencial nas ações para ética, é o exercício crítico envolvendo pensamento, ação, experiência, diferença, valores.

Menezes (2001) aborda que a interdisciplinaridade seria um meio de se obter à transdisciplinaridade. A interdisciplinaridade considera um diálogo entre as disciplinas, porém permanece na estrutura da disciplinaridade. Já a transdiciplinaridade alcançaria um estágio onde não haveria mais fronteiras entre as disciplinas e se consideraria outras fontes e níveis de conhecimento. Os Parâmetros Curriculares Nacionais (PCNs) orientam para alguns princípios básicos da educação que seriam o pluralismo de ideias e concepções pedagógicas, na perspectiva da inter, multi e transdisciplinaridade.

Santana (2016) reforça que no processo educacional é imprescindível recorrer à transdisciplinaridade, a qual, desde o século XX, vem se desenvolvendo no meio acadêmico, visando conectar o campo universitário ao restante da sociedade, distanciados justamente pela tendência à máxima especialização profissional. A utilização cada vez mais frequente vem permitindo não só a formação de especialistas, mas de profissionais com uma bagagem mais ampla, preparados para enfrentar o mercado de trabalho.

A Constituição Federal trata a educação como um direito de todos e um dever do Estado e a Educação Ambiental e deve ter como base o pensamento critico e inovador, uma vez que a Educação Ambiental pode acontecer em que lugar e em qualquer tempo, de modo formal não formal e informal.

Um dos principais objetivos da Educação Ambiental é promover a transformação social, uma vez que a mesma não acontece só dentro das escolas, mas em todos os espaços da sociedade podendo ocorrer de maneira individual e coletiva com o propósito de formar cidadãos com consciência que seja capaz de se importar com os problemas globais, observando suas causas e inter-relações em uma perspectiva sistêmica, em seus contextos sociais e históricos. 
Research, Society and Development, v. 7, n. 12, p. 01-22, e2712478, 2018

ISSN 2525-3409 (CC BY 4.0)

Sorrentino e Trajber (2007) consideram que na educação escolar, em todos os níveis e modalidades de ensino, o Órgão Gestor - especificamente o MEC - tem o dever de apoiar a comunidade escolar - professores, estudantes, direção, funcionários, pais e amigos - a se tornarem educadores e educadoras ambientais com uma leitura crítica da realidade, uma leitura da palavra-mundo conforme Paulo Freire.

Para Virgens (2011) os professores devem ser capacitados para trabalharem questões ambientais em sala de aula. Sendo assim, devem ser preparados para decodificar as informações que recebem, principalmente as ambientais e ajudar os alunos a construir um conhecimento significativo dentro da educação ambiental. A formação profissional do docente proporciona atividade reflexiva constante, perante mudanças sociais e culturais, pois a missão do professor é árdua na tentativa de formar cidadãos críticos, capazes de se adaptar as exigências sociais.

Medina (2001) afirma que a formação voltada à educação ambiental que o professor necessita se relaciona aos processos de construção e reconstrução de conhecimentos e valores no contexto escolar, disciplinas e da organização do trabalho docente, revendo seus conhecimentos e valores, pois a função da escola oscila conforme os valores sociais pertinentes em cada sociedade, pois o professor precisa refletir sua prática em sala de aula e propor iniciativas para que ocorram mudanças necessárias na sua formação que deve ser continua.

Virgens (2011) diz ainda que o sucesso do ensino em sala de aula depende da forma como o professor conduz as suas atividades, adequando-as necessidades dos alunos, por isso se faz necessário a reflexão diária sobre tudo que está no seu contexto de vida presente e futura. O professor deve se ver como um agente de transformação social e trabalhar reflexivamente em busca a modificar a realidade por meio do desenvolvimento de valores como criticidade, autonomia, liberdade de pensamento e ação. Para que isso se realize é necessário que os professores busquem essas qualificações e não fiquem parados apenas nas construções tradicionalistas.

\subsection{Práticas Ambientais em Sala de Aula}

De acordo com o artigo 10 da Lei $n^{\circ} 9.795$ de 27 de abril de 1999: "a educação ambiental será desenvolvida como uma prática educativa integrada, contínua e permanente em todos os níveis e modalidades do ensino formal, não devendo ser implantada como disciplina específica.".

Cerqueira (2017) diz que a Educação Ambiental visa proporcionar uma conscientização ambiental em meio a um processo de alfabetização ecológica, podendo ser 
abordada de diferentes formas na sala de aula, onde o professor deve se utilizar de metodologias criativas para obter uma atenção e participação dos seus alunos. O autor defende ainda que devem ser desenvolvidas atividades práticas, de forma que auxilie os alunos a conciliar teoria e prática, como por exemplo, aulas em zoológicos, parques, pátio da escola, onde haja as explicações e o contato com os recursos naturais. Existem também ações que devem ser solicitadas tanto no convívio na instituição de ensino como nas residências dos alunos, por exemplo, a coleta seletiva do lixo, a redução no desperdício de água, entre outras atitudes que contribuem com o meio ambiente, a qual irá proporcionar que eles sejam agentes participativos do processo de ensino aprendizagem e, principalmente, visualizando o resultado e havendo uma mudança comportamental.

Guimarães (2007) aborda que essa é uma educação voltada para uma ação-reflexiva, coletiva, para a relação interativa em que seu conteúdo está para além dos livros, está na realidade socioambiental ultrapassando os muros das escolas. É uma Educação política voltada para a intervenção social entendida como um ambiente educativo e que contribui para a transformação da sociedade em suas relações, capaz de construir utopias como sendo o inédito viável dos que acreditam e lutam individualmente e coletivamente pela possibilidade de um mundo melhor. No processo, o educando deve ser estimulado a uma reflexão crítica para se transformar individualmente e, ao mesmo tempo, subsidiar uma prática que busque intencional e coletivamente transformar a sociedade. Esse processo de conscientização se dá por intermédio de uma formação cidadã comprometida com o exercício do enfrentamento das questões socioambientais da atualidade. Para tanto é desejável a criação de um ambiente educativo que propicie a oportunidade de conhecer, sentir, experimentar; ou seja, vivenciar aspectos outros aos que predominam na constituição da atual realidade socioambiental. Isso poderá potencializar uma prática diferenciada que, pelo incentivo à ação cidadã em sua dimensão política, repercuta em novas práticas sociais voltadas para a sustentabilidade socioambiental.

\section{Metodologia}

O trabalho foi desenvolvido através de pesquisa bibliográfica, para a compreensão das propostas educacionais acerca da Educação Ambiental, bem como discutir o envolvimento com a Gestão Ambiental.

A pesquisa bibliográfica possibilita um amplo alcance de informações, além de permitir a utilização de dados dispersos em inúmeras publicações, auxiliando também na construção, ou na melhor definição do quadro conceitual que envolve o objeto de estudo 
proposto. Ainda em relação à pesquisa bibliográfica, segundo Gil (2008) este tipo de pesquisa é desenvolvida a partir de material já elaborado por outros pesquisadores. Neste caso o pesquisador coleta informações sobre pesquisas anteriores em fontes bibliográficas, tais como: Livros, publicações periódicas e obras acadêmicas.

Além de se constituir como pesquisa qualitativa. A pesquisa qualitativa não se preocupa com representatividade numérica, mas, sim, com o aprofundamento da compreensão de um grupo social, de uma organização, etc. Os pesquisadores que adotam a abordagem qualitativa opõem-se ao pressuposto que defende um modelo único de pesquisa para todas as ciências, já que as ciências sociais têm sua especificidade, o que pressupõe uma metodologia própria. Assim, os pesquisadores qualitativos recusam o modelo positivista aplicado ao estudo da vida social, uma vez que o pesquisador não pode fazer julgamentos nem permitir que seus preconceitos e crenças contaminem a pesquisa (SEVERINO, 2008, p. 34).

Dessa forma, é possível utiliza-se de várias informações acerca do assunto, bem como opiniões de diversos autores, promovendo uma melhor compreensão e debate sobre o conteúdo, auxiliando a relacionando as abordagens tratadas entre educação, meio ambiente e a gestão ambiental.

\section{Considerações Finais}

A Educação Ambiental objetiva a disseminar o conhecimento sobre o meio ambiente, buscando auxiliar na sua preservação e manter a sustentabilidade de seus recursos, para que a partir do conhecimento, em um processo contínuo, os seres humanos percebam com outros olhos suas ações e possam agir em busca de soluções para os problemas ambientais presentes e futuros, adquirindo conhecimentos, valores, habilidades, experiências e determinação. Sendo assim, a Educação Ambiental passa a se tratar de um processo que deve ser instaurado em todas as ações educativas, e não apenas em uma disciplina, pois deve compreender uma ideia crítica e global evidenciando valores, estimulando a participação e promovendo a cidadania.

A partir dessa necessidade, a escola deve tratar a transdisciplinaridade com um enfoque pluralista do conhecimento objetivando atingir uma unificação do saber, a qual se unem várias disciplinas para facilitar um exercício mais amplo da cognição humana. A ideia de transdiciplinaridade surge, portanto, da necessidade de substituir o conceito de disciplinas, possibilitando vivenciar um processo que envolve uma lógica de trabalho diferenciada, uma maneira mais ampla de pensar a realidade. 
A Educação Ambiental deve ter como base um pensamento crítico e inovador, promovendo a transformação social em todos os espaços da sociedade, podendo ocorrer de maneira individual e coletiva com o propósito de formar cidadãos com consciência que seja capaz de se importar com os problemas globais, observando suas causas e inter-relações em uma perspectiva sistêmica, em seus contextos sociais e históricos. Importante destacar que a educação ambiental não é uma prática educativa desassociada da realidade social, onde o educando tem o direito de refletir livremente, debater e realizar suas escolhas.

A partir da discussão apresentada neste trabalho, por meio da transdiciplinaridade, pode-se perceber que a Educação Ambiental pode atuar como um Instrumento de Gestão Ambiental eficaz e eficiente, onde se busca trabalhar conceitos, valores e comportamentos da sociedade como um todo, podendo se aliar a outros instrumentos econômicos de controle com finalidade de contribuir para a construção de uma sociedade a qual prioriza o equilíbrio de todo o meio ambiente.

A educação ambiental deve estimular a solidariedade, a igualdade e o respeito aos direitos humanos, valendo-se de estratégias democráticas e intenção entre as culturas. Deve estimular e potencializar o poder das diversas populações promoverem oportunidades para as mudanças democráticas de base que estimulem os setores populares da sociedade. Isto implica que as comunidades devem retomar a condução de seus próprios destinos. Deve valorizar as diferentes formas de conhecimento, pois este é diversificado acumulativo e produzido socialmente, não devendo ser patenteado ou monopolizado.

É dever de a educação ambiental integrar conhecimentos, aptidões, valores, atitudes e ações. Deve converter cada oportunidade em experiências educativa de sociedades sustentavam. A educação ambiental deve ajudar a desenvolver uma consciência étnica sobre as formas de vida com as quais compartilhamos este planeta e respeitar seus ciclos vitais.

O presente estudo contribuiu no envolvimento e na busca para discutir conceitos e abordagens de autores relacionados a consciência ética e ao processo desenvolvido nas instituições de ensino, objetivando a transdisciplinaridade, a qual envolve o aluno no contexto de modo integrado aos demais conteúdos, sem a distinção. Além disso, trouxe a apresentação da inter-relação da Educação Ambiental como perspectiva transdisciplinar com os Sistemas de Gestão Ambiental. A união desses conceitos, que visa implementar essa prática de gestão ambiental em uma abordagem transdisciplinar, permite trazer um conhecimento e uma capacidade crítica ao indivíduo, capacitando-o a dialogar e agir de forma contínua e permanente. 
Partindo dos conceitos trabalhados no decorrer desse trabalho, para novas pesquisas, sugere-se que seja realizada a aplicação do estudo nas instituições de ensino, a fim de comparar a teoria explicitada com a realidade na prática. Embora a legislação indique a educação ambiental como meio curricular, não há disciplina específica, deixando a critério da instituição como implementar esse conteúdo a seus alunos, sendo assim, através de uma pesquisa empírica pode ser coletada informações relevantes de como essas práticas são realizadas.

\section{Referências}

ADAMS, B. G. A importância da lei 9.795/99 e das diretrizes curriculares nacionais da educação ambiental para docentes. Monografias Ambientais, REMOA/ UFSM, 2012. ALCÂNTARA et al., v(5), n5, p. 734 - 740, 2012. Revista Eletrônica em Gestão, Educação e Tecnologia Ambiental REGET/UFSM.

BRASIL. Lei $N^{\circ}$ 6.938, de 31 de Agosto de 1981. Dispõe sobre a Política Nacional do Meio Ambiente, seus fins e mecanismos de formulação e aplicação, e dá outras providências. Disponível em: < http://www.planalto.gov.br/ccivil_03/Leis/L6938.htm> Acesso em: 17/06/2018.

BRASIL. Lei n. 9795 - 27 de abril de 1999. Dispõe sobre a educação ambiental. Política Nacional de Educação Ambiental. Brasília, 1999.

BRASIL. Constituição (1988). Constituição da República Federativa do Brasil. Brasília, DF: Senado Federal: Centro Gráfico, 1988. p.292.

CARVALHO, Isabel Cristina de Moura. Educação ambiental: Formação do sujeito ecológico. 2. ed. São Paulo: Cortez, 2006.

CASTRO, Ronaldo Souza de. A construção de conceitos científicos: uma contribuição para a educação ambiental. In: XXII Encontro Nacional de Professores do PROEPRE, 2004, Águas de Lindóia. XXI Encontro Nacional de Professores do PROEPRE, 2004. CERQUEIRA, W. A Educação Ambiental na Sala de Aula. Disponível em: http://educador.brasilescola.uol.com.br/estrategias-ensino/a-educacao-ambiental-na-salaaula.htm Acesso em: 10/07/2018.

FLORIANO, Eduardo Pagel. Políticas de gestão ambiental, 3ed. Santa Maria: UFSM-DCF, 2007.

GIL. Antonio Carlos. Métodos e técnicas de pesquisa social. 6. ed. São Paulo : Atlas, 2008. GUIMARÃES, M. Políticas de Educação Ambiental do Órgão Gestor. Vamos cuidar do Brasil: Conceitos e Práticas em Educação Ambiental. [Coordenação: Soraia Silva de Mello, Rachel Trajber]. - Brasília: Ministério da Educação, Coordenação Geral de Educação Ambiental: Ministério do Meio Ambiente, Departamento de Educação Ambiental: UNESCO, 2007.

HARGREAVES, Andy; FINK, Dean 2007. Liderança sustentável. Porto: Porto Editora, 2007. 
Layrargues, P. P. Muito Além da Natureza: Educação Ambiental e Reprodução Social. In: Loureiro, C.F.B.; Layrargues, p.P. \& Castro, R.C. De (Orgs.) Pensamento complexo, dialética e educação ambiental. São Paulo: Cortez. p. 72-103. 2006.

LAYRARGUES, P.P. A crise ambiental e suas implicações na educação. In: QUINTAS, J.S. (Org.) Pensando e praticando a educação ambiental na gestão do meio ambiente. 2 a edição. Brasília: IBAMA. p. 159-196. 2002.

MACHADO, P.A.L. Direito Ambiental Brasileiro. $19^{a}$ edição, revista, atualizada e ampliada. São Paulo: Malheiros Editores, 2011.

MEDINA, N. M. A formação dos professores em Educação Ambiental. In: Panorama da educação ambiental no ensino fundamental / Secretaria de Educação Fundamental - Brasília : MEC ; SEF, 2001.

MENEZES, Ebenezer Takuno de; SANTOS, Thais Helena dos. Verbete mediação pedagógica. Dicionário Interativo da Educação Brasileira - Educabrasil. São Paulo: Midiamix, 2001. Disponível em: <http://www.educabrasil.com.br/mediacao-pedagogica/>. Acesso em: 10 de jul. 2018.

MINISTÉRIO DA EDUCAÇÃO - CONSELHO NACIONAL DE EDUCAÇÃO. RESOLUÇÃO N 2, DE 15 DE JUNHO DE 2012. "Estabelece as Diretrizes Curriculares Nacionais para a Educação Ambiental.” Disponível em: <

http://portal.mec.gov.br/index.php?option=com_docman\&view=download\&alias=10988rcp002-12-pdf\&category_slug=maio-2012-pdf\&Itemid=30192> Acesso em: 10/07/2018. MINISTÉRIO DO MEIO AMBIENTE. Identidade da educação ambiental brasileira. Brasília (DF): MMA, 2004. Disponível em:

http://www.mma.gov.br/estruturas/educamb/_arquivos/livro_ieab.pdf.Acesso em: 13/07/2018. PEREIRA, Pedro Henrique Santana; TERZI, Alex M.. Aspectos gerais da Lei de Educação Ambiental e a problemática da transversalidade em sua aplicação nas escolas. In: Âmbito Jurídico, Rio Grande, XIII, n. 75, abr 2010. Disponível em:

<http://www.ambitojuridico.com.br/site/index.php?n_link=revista_artigos_leitura\&artigo_id= 7348>. Acesso em 10/07/2018.

QUINTAS, J.S. Repensar a educação ambiental: um olhar crítico/ Carlos Frederico Bernardo Loureiro, Philippe Pomier Layrargues, Ronaldo Souza de Castro (orgs). - São Paulo: Cortez, 2009.

Resolução CONAMA No 306/2002 . "Estabelece os requisitos mínimos e o termo de referência para realização de auditorias ambientais". - Data da legislação: 05/07/2002 Publicação DOU nº 138, de 19/07/2002, págs. 75-76 . Status: Alterada pela Resolução no 381, de 2006.

Sabbagh, R.B. Gestão Ambiental. Cadernos de Educação ambiental. Governo do Estado De São Paulo. Secretaria do Meio Ambiente São Paulo - 2011.

SANTANA, A.L. Transdisciplinaridade. Infoescola-Educação. Disponível em: <http://www.infoescola.com/educacao/transdisciplinaridade/>. Acesso em: 10/07/2018. SEVERINO.Antonio Joaquim. : Metodologia do Trabalho Científico. 23a edição: revista e atualizada .São Paulo: Cortez,2008.

SILVA, D. G. A importância da educação ambiental para a sustentabilidade. FAFIPA, São Joaquim - PR. 2012 Disponível em: <http://www.uniedu.sed.sc.gov.br/wpcontent/uploads/2014/04/DANISE-GUIMARAES-DA-SILVA.pdf >. Acesso em: 10/07/2018. 
SILVA, M. R.; PESSOA, Z. S. Educação como instrumento de gestão ambiental numa perspectiva transdisciplinar. IN: NUCLEO RM NATAL: OBSERVATORIO DAS METROPÓLES. Natal - UFRN, 2013

SILVA, D.J.P. ENTENDENDO A ISO 14000. Série Sistema de Gestão Ambiental. Universidade Federal de Viçosa Departamento de Tecnologia de Alimentos Ciência e Tecnologia de Alimentos. Viçosa-MG/Janeiro/2011.

Sorrentino,M; Trajber,R. Políticas de Educação Ambiental do Órgão Gestor. Vamos cuidar do Brasil: Conceitos e Práticas em Educação Ambiental. [Coordenação: Soraia Silva de Mello, Rachel Trajber]. - Brasília: Ministério da Educação, Coordenação Geral de Educação Ambiental: Ministério do Meio Ambiente, Departamento de Educação Ambiental : UNESCO, 2007.

VIRGENS, R.A. A Educação Ambiental no Ambiente Escolar. Universidade de Brasília, UNB. Brasília, 2011. 